Document downloaded from:

http://hdl.handle.net/10251/46457

This paper must be cited as:

Eiras Fernández, JN.; T.Kundu; Bonilla Salvador, MM.; Paya Bernabeu, JJ. (2013). Nondestructive monitoring of ageing of Alkali resistant Glass fiber reinforced cement (GRC). Journal of Nondestructive Evaluation - NDT and E International. 32:300-314. doi:10.1007/s10921-013-0183-y.

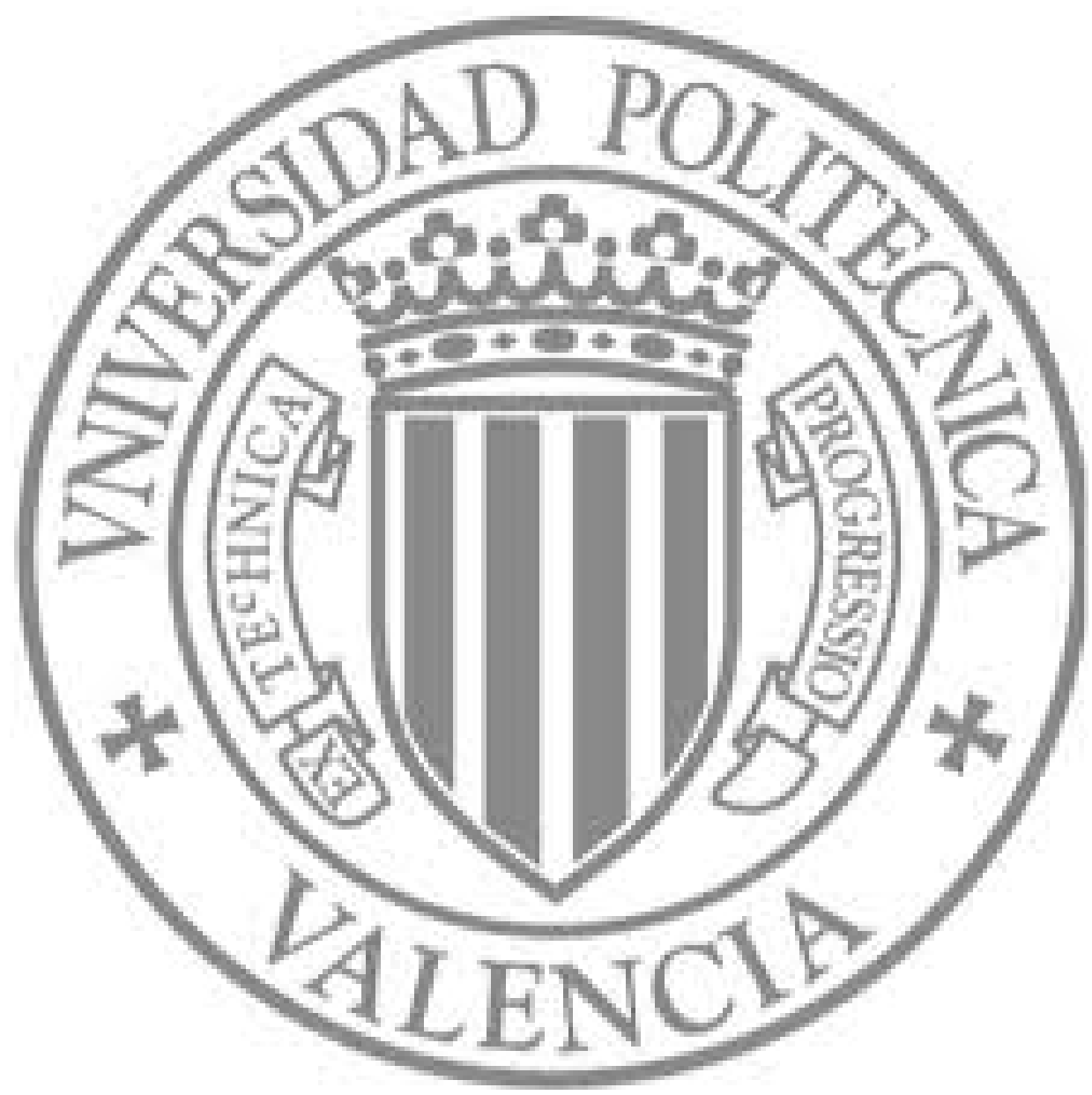

The final publication is available at

http://dx.doi.org/10.1007/s10921-013-0183-y

Copyright Elsevier 


\section{Nondestructive Monitoring of Ageing of Alkali Resistant Glass Fiber Reinforced Cement (GRC)}

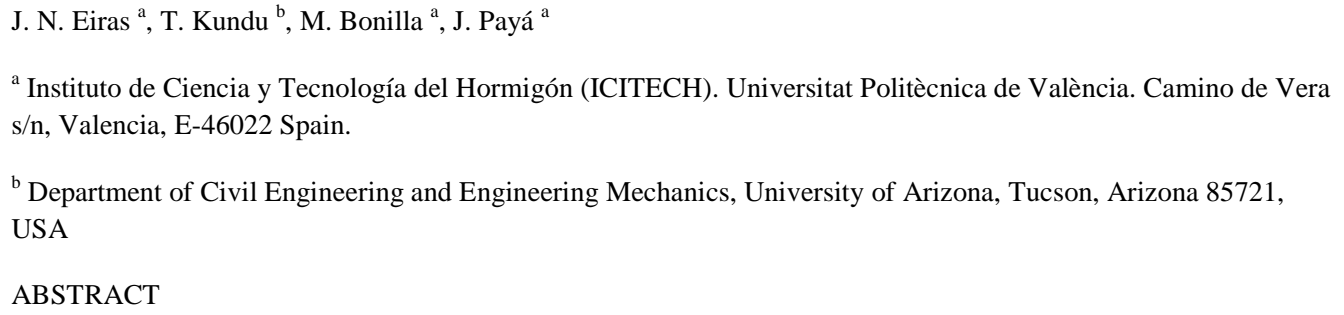

Glass fiber reinforced cement (GRC) is a composite material made of portland cement mortar and alkali resistant (AR) fibers. AR fibers are added to portland cement to give the material additional flexural strength and toughness. However ageing deteriorates the fibers and as a result the improvement in the mechanical properties resulted from the fiber addition disappears as the structure becomes old. The aim of this paper is monitoring GRC ageing by nondestructive evaluation (NDE) techniques. Two different NDE techniques - 1) nonlinear impact resonant acoustic spectroscopy analysis and 2) propagating ultrasonic guided waves - are used for this purpose. Both techniques revealed a reduction of the nonlinear behavior in the GRC material with ageing. Specimens are then loaded to failure to obtain their strength and stiffness. Compared to the un-aged specimens the aged specimens are found to exhibit more linear behavior, have more stiffness but less toughness. Finally, undisturbed fragments on the fracture surface form mechanical tests are inspected under the electron microscope, to understand the fundamental mechanisms that cause the change in the GRC behavior with ageing.

Keywords: Glass Fiber Reinforced Cement, Material Ageing, Ultrasonic Guided Waves, Nonlinear Impact Resonant Acoustic Spectroscopy, Nondestructive Evaluation.

\section{Introduction}

Alkali resistant glass fiber reinforced portland cement is a cement-based composite material that has higher flexural strength and toughness than plain cement [1]. However, GRC undergoes a rapid ageing process especially in humid and alkaline environment $(\mathrm{pH}>12)$. This ageing can nullify the positive effects of glass fibers undergoing from a ductile to a brittle material. The loss of mechanical properties with ageing has been attributed to two different mechanisms - a stress corrosion cracking process in glass materials called static fatigue [2] and the growth of 
hydration products, mainly portlandite around the single filaments in the strand [1]. This concern relegates GRC mainly to nonstructural applications, such as façade panels, acoustic barriers, permanent formwork or cladding tunnels. Recent applications of GRC as structural material have been investigated in telecommunication towers by combining carbon fiber, glass fiber and steel reinforcement [3].

Different strategies for improving the durability of GRC have been attempted by modifying the fibers and/or by altering the alkalinity of the matrix [7-9]. All these improvements have been evaluated by mechanical tests after accelerated ageing. Accelerated ageing tests have been broadly accepted for testing the durability of GRC. They can be classified as i) Deemed to satisfy tests, (EN 1170-8 [10]) where the GRC specimens are exposed to severe conditions, and ii) predictive accelerated ageing tests [11] that are commonly used to predict the service life of the material, in real weather conditions. For example, Purnell et al. [2] established that GRC soaked for 1 day in water at $55^{\circ} \mathrm{C}$, corresponds to 100 days of exposure to the real weather conditions in the United Kingdom. However, it should be noted that the correspondence between the accelerated ageing tests and the real aging conditions is still being investigated, especially when different matrix compositions are to be compared [11-12]. Typically the ageing process has been assessed by mechanical testing or by strand in cement (SIC) tests [13-14]. The aim of this work is to assess the ageing process in GRC by two nondestructive testing techniques - 1) resonance frequency tests at different impact energy levels called Nonlinear Impact Resonance Acoustic Spectroscopy (NIRAS) and 2) Ultrasonic Guided Wave (UGW) tests. GRC specimens are subjected to accelerated ageing by placing them in water baths at elevated temperatures. NIRAS and UGW tests are conducted on aged and un-aged specimens to study the effect of ageing on different parameters measured by these tests. The specimens are then loaded to failure and fragments from the fracture surface of the specimens are inspected under the electron microscope to investigate the effect of ageing on the strength, toughness and internal composition of GRC specimens. The final objective of this research is to be able to monitor the health (strength and toughness) of GRC by nondestructive testing, and to understand why and how this material degrades with time. 


\section{Background}

\subsection{Nonlinear Impact Resonant Acoustic Spectroscopy}

In general, cement based materials as a result of their intrinsic heterogeneities, can be classified as Nonlinear Mesoscopic Elastic (NME) materials [15]. This particular behavior is manifested as a frequency shift in their resonant frequencies known as fast dynamic effect. Experimental findings have demonstrated that fast dynamic effect is related to hysteresis in the strain-stress relationship [16]. After Guyer et al. [17] a phenomenological model to describe the hysteresis in the Preisach-Mayergoyz space [18] can be written as:

$E=E_{o}\left[1+\beta \varepsilon+\delta \varepsilon^{2}+\alpha(\Delta \varepsilon+\operatorname{sign}(\dot{\varepsilon}))\right]$

where $E_{0}$ is the linear elastic modulus, $\beta$ and $\delta$ are the cubic and quartic anharmonicities, $\varepsilon$ is strain, $\Delta \varepsilon$ is the strain amplitude, $\dot{\varepsilon}$ is the strain rate due to hysteresis, and sign is the sign function which is equal to 1 if $\dot{\varepsilon}>0,-1$ if $\dot{\varepsilon}<0$ and 0 if $\dot{\varepsilon}=0$. The hysteresis nonlinearity parameter $\alpha$ is a measure of the material hysteresis and is related to the fast dynamics as follows [19].

$\frac{f_{o}-f}{f_{o}}=\alpha \cdot \Delta \varepsilon$

where $f_{0}$ is the linear resonance frequency and $f$ is the resonance frequency with increasing strain amplitude. NIRAS technique requires exciting the resonant frequencies at different energy levels. The main advantage of NIRAS measurements is that multiple modes are generated with a single impact and their corresponding dynamic nonlinear parameter $\alpha$ can be obtained. It has been demonstrated that $\alpha$ is a sensitive indicator of damage in cement based materials subjected to alkali silica reaction [20-21], carbonation [22] and compressive mechanical damage [23]. Boundary conditions and sample shape differ in our study from those of others. In this study we report the hysteretic parameter $\alpha$ for various vibration modes and its sensitivity to the ageing process of GRC.

\subsection{Ultrasonic Guided Waves - Linear and Nonlinear Techniques}

Traditionally, linear ultrasonic inspection technique is used for detection of material damage or anomalies. Macroscopic anomalies such as cracks, notches, inclusions and corrosions can be detected in this manner by propagating ultrasonic bulk waves or guided waves [24-25] through the specimen. The wave is reflected by the anomaly or transmitted through it undergoing mode conversion because of the linear interaction between the 
anomaly and the propagating wave. Only macroscopic anomalies having dimensions in the order of the wavelength or larger can be detected in this manner while anomalies that are much smaller than the wavelength remain hidden to the linear ultrasonic technique. However, the presence of smaller anomalies can be detected by the nonlinear ultrasonic method. The nonlinear ultrasonic techniques are classified primarily under two categories - (i) those based on the generation of higher harmonics [26] and (ii) those based on the generation of the side bands [27].

If an ultrasonic signal of frequency $\omega$ is sent through a linear specimen its frequency remains unchanged. However, a nonlinear specimen alters the frequency of the propagating wave. The signal propagating through a non-linear specimen contains frequency components that are different from the original frequency $\omega$. When the received signal frequency $\Omega_{i}\left(\Omega_{i}=n_{i} \omega\right)$ is an integer multiplier of the original frequency $\omega$, then the generated signals are called higher harmonics. The degree of nonlinearity of the material can be related to the strength of the higher harmonic signals using the $\beta$-factor [25]. If the high frequency signal is modulated by a high amplitude low frequency signal then the spectral plot of the received signal shows several smaller frequency peaks at $\Omega_{i}\left(=\omega \pm k \omega_{i}\right)$ near the high frequency peak at $\omega$. These frequencies $\Omega_{i}$ are not integral multipliers of $\omega$ and are called sidebands. The degree of nonlinearity is related to the strength of the sidebands. Higher the material nonlinearity stronger are the sidebands.

\section{Experimental Investigation}

\subsection{Specimen Fabrication}

GRC specimens of dimension 225x50x10 mm were produced following the European standard EN 1170. The samples were made from cement of type CEM I/52.5R EN 197-1 and siliceous aggregate with cement-aggregate proportion of 1:1 and a fineness modulus of 3.1. Water to cement ratio was taken as 0.35 and Glenium ACE 32 superplasticizer was added ( $0.43 \%$ of cement weight) in order to obtain a slump of $165 \mathrm{~mm}$ as instructed in EN 1170-1 [28]. Non dispersible AR Glass fibers CemFil with a length of $12 \mathrm{~mm}$ were added to the mortar. The fiber weight was $3 \%$ of the mortar weight.

The specimens were stored at $20^{\circ} \mathrm{C}$ and relative humidity of $100 \%$. After more than 28 days of curing, the specimens were aged in a hot water bath at $65^{\circ} \mathrm{C}$. Two different types of nondestructive inspections were conducted to assess the ageing process: NIRAS and UGW. Then mechanical testing and scanning electron microscopy observations were performed. 


\subsection{Inspection Methods}

\subsubsection{Nonlinear Impact Resonant Acoustic Spectroscopy}

NIRAS test was conducted on un-aged and aged specimens after 40, 80, 120 and 150 hours of ageing. An impact hammer (Bruel \& Jaer 8206, $22.7 \mathrm{mV} / \mathrm{N}$ ) with an aluminum tip struck the prismatic sample, in order to excite the resonant frequencies of vibration. The computer program acquired 8192 points, with a sampling frequency of 50 KHz. An accelerometer $\left(0.956 \mathrm{mV} / \mathrm{m} / \mathrm{s}^{2}\right)$ sensed the excitation. Two different test configurations, as shown in figure 1, were tried out in order to generate the resonant modes. Test configuration 1 generated five resonant frequencies while test configuration 2 showed only three resonant peaks.

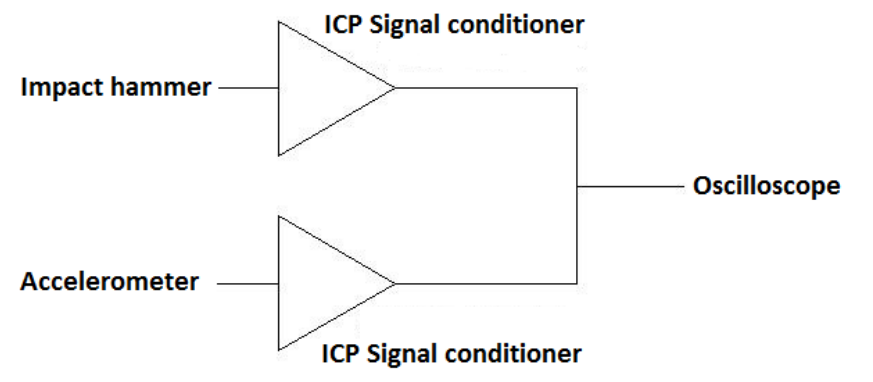

\section{a)}
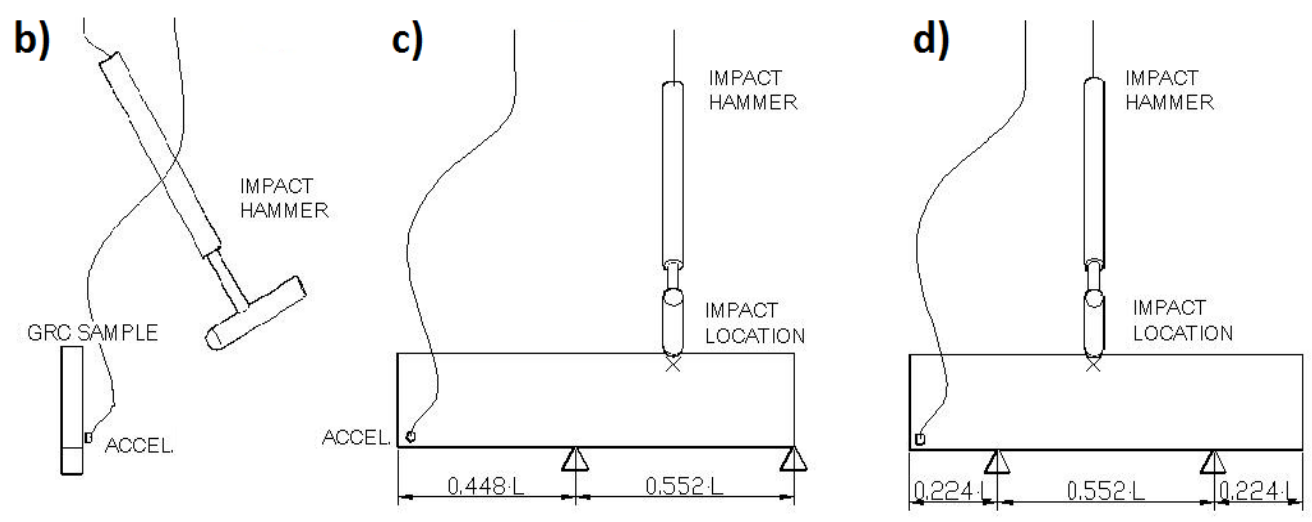

Figure1. Schematic diagram of NIRAS test a) Schematic set up b) Lateral view of set-up c) Configuration $1 \mathrm{~d}$ ) 
The eigen value problem for the prismatic specimen was solved numerically using ANSYS 13.0 to obtain different eigen-frequencies or resonance frequencies of the specimen. Comparing the computed eigen frequency values with the frequency peaks obtained in the experimental spectra different vibration modes associated with the recorded frequency peaks were identified. The eigen-frequency solution is a particular case of singular value decomposition problem. The Block-Lanczos algorithm was used in the ANSYS 13.0 software considering GRC as a linear isotropic material to extract vibration modes in the frequency range 0 to $7 \mathrm{kHz}$. The results are shown in figure 2 .

a)

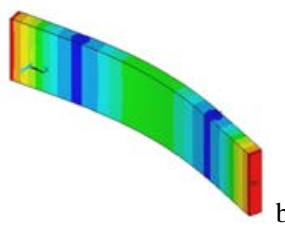

e)

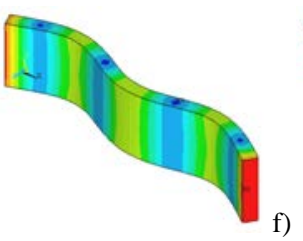

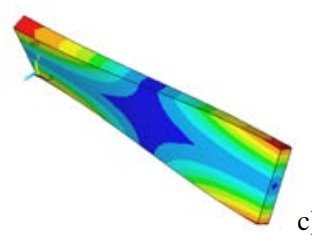

c)

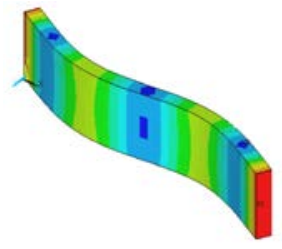

d)
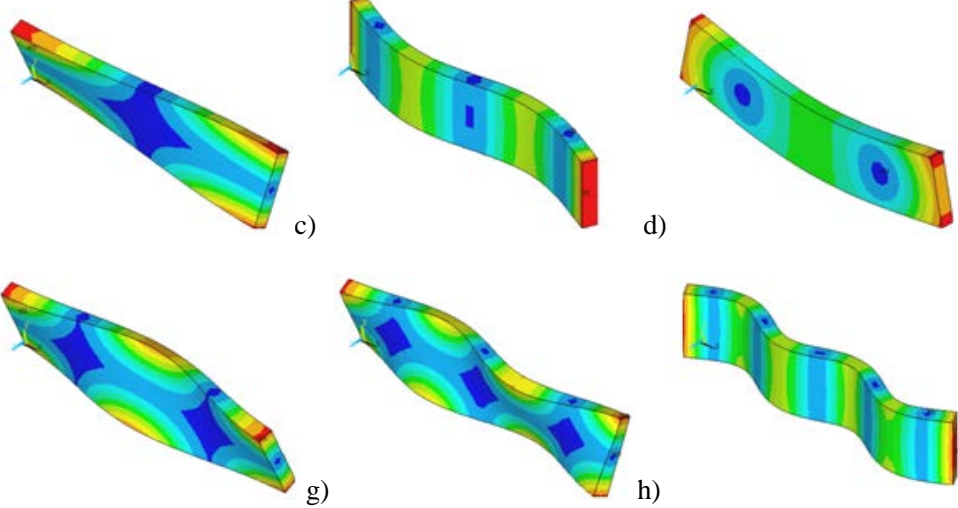

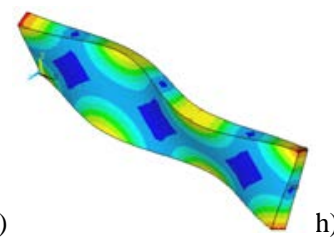

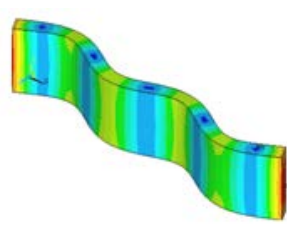

Figure 2. Vibration mode shapes for different eigen frequencies, Density=2100 kg/m $\mathrm{m}^{3}$, Poisson's ratio $0.2, \mathrm{E}=32$

GPa. Flexural and torsional modes are denoted by FLEX and TOR, respectively and shown in Figures 2a to 2h: a)

C1FLEX= 787.913 Hz, b) C1TOR=2068.05 Hz, c) C2FLEX=2149.44 Hz, d) C1FLEXYZ= $3444.57 \mathrm{~Hz}$, e)

C3FLEX=4148.94 Hz, f) C2TOR=4218.57 Hz, g) C3TOR=6524.11 Hz, h) C4FLEX=6719.18 Hz.

The identification of higher flexural and torsional resonance modes are difficult since at the higher frequency range several modes show very close resonance frequencies, e.g. first torsional and second flexural (experimental values F1TOR and F2FLEX or theoretical values C1TOR and C2FLEX, as shown in Figure 2) or third flexural and second torsional (F3FLEX and F2TOR). In order to discern among resonance modes that are very close, modal shapes were determined (Figures 3a and 3b) and two test configurations were tried out as shown in Figure 1. Since the test configuration 2 struck the sample at nodal points of F1TOR, F2FLEX and F3TOR these modes were poorly excited by this strike. However F3FLEX and F2TOR were properly excited. In this manner from the resonance peaks generated by the two test configurations one can determine the resonance frequencies corresponding to all vibration modes. Experimental and theoretical values are compared in Figure 4. Experimental peaks for flexural and torsional 
modes are denoted as $F_{j} F L E X$ and $F_{j}$ TOR ( $j=1,2$ or 3 ), respectively. On the same graph theoretical values are plotted by dashed lines and denoted as $\mathrm{C}_{\mathrm{j}} \mathrm{FLEX}$ and $\mathrm{C}_{\mathrm{j}} \mathrm{TOR}$. After matching the experimental and theoretical values of resonance frequencies the first and second flexural modes (F1FLEX, F2FLEX), and first, second and third torsional modes (F1TOR, F2TOR, F3TOR) were identified in the experimental spectra. Finally, the test configuration 1 was adopted since with this configuration we obtained five resonance peaks of relatively high amplitude against only three resonance modes in the test configuration 2 .
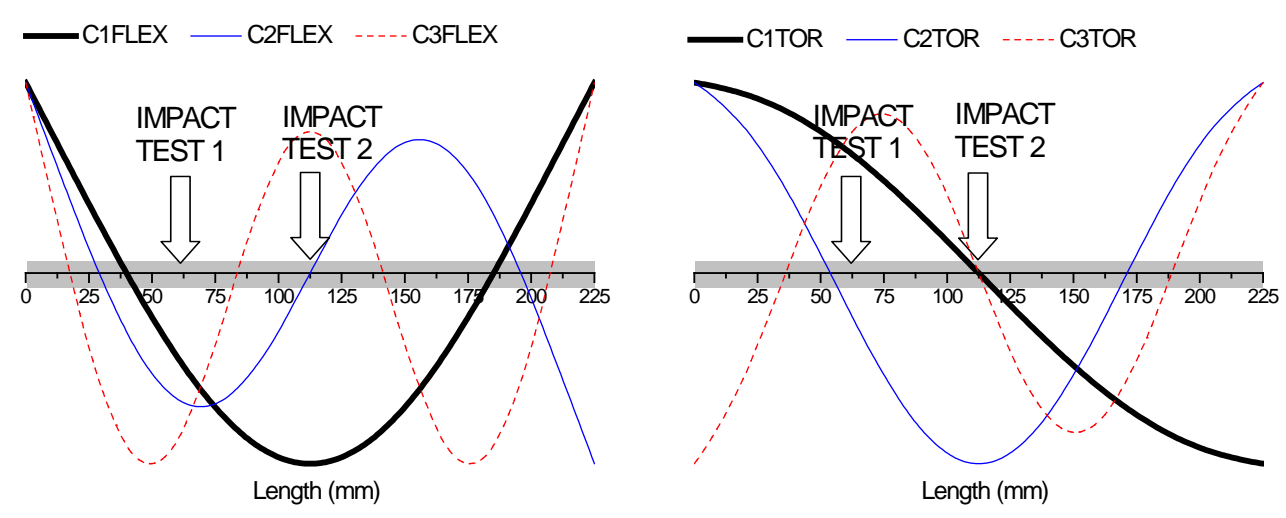

a)

b)

Figure 3. Mode shapes for computed eigen frequencies a) Flexural modes (C1FLEX, C2FLEX and C3FLEX), b)

Torsional modes (C1TOR, C2TOR, C3TOR). 


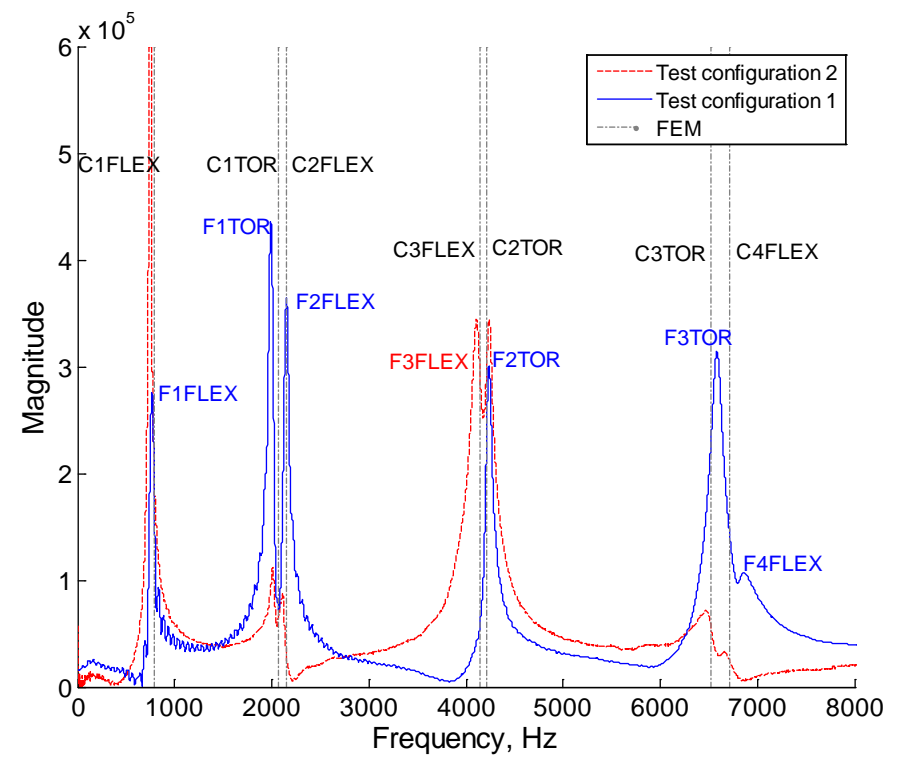

Figure 4. Experimental spectra of an un-aged specimen and computed (FEM) resonance frequencies are shown by dashed lines.

\subsubsection{Ultrasonic Guided Waves}

Ultrasonic guided waves were propagated through un-aged and aged specimens. Aged specimens were soaked in hot water for 150 hours. Two PZT (Lead-Zironate-Titanate) transducers were placed in direct contact with the GRC specimen at its two ends, on the same side of the specimen as shown in Figure 5. To provide a good contact for the ultrasonic signals a few drops of water were placed between the transducers and the specimen to make the interface wet. A pulse generator Panametrics-NDT ${ }^{\mathrm{TM}}$ Model 5058PR High Voltage pulser-receiver was used to excite one transducer that transmitted the signal into the specimen. The other transducer recorded the propagated ultrasonic energy. The propagated signal was digitally recorded by 25000 points with a sampling frequency of $25 \mathrm{MHz}$. 

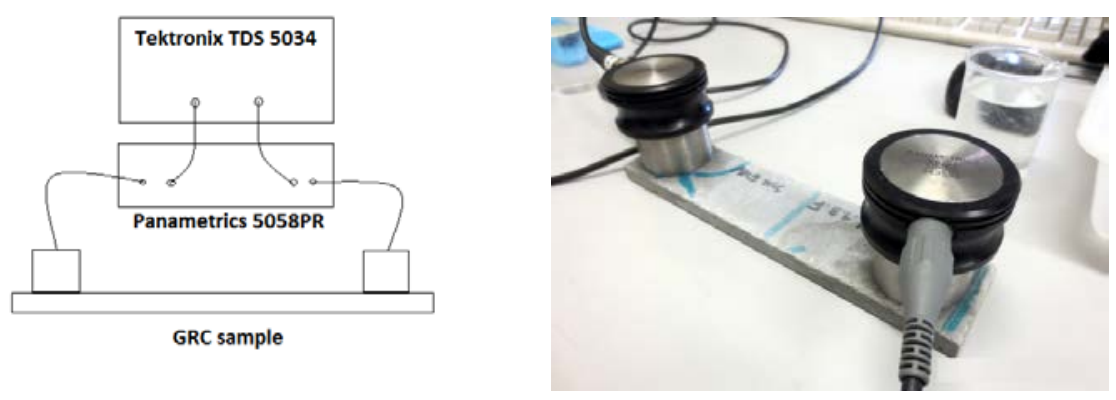

Figure 5. Test setup for UGW experiments

\subsubsection{Mechanical test}

Four point bending test was performed in accordance with the European standard EN 1170-5 [29]. Two un-aged and two aged (150 hours) specimens were tested in INSTRON universal testing machine (Model 3382) as shown in Figure 6. They were loaded in the displacement control environment at a rate of $1 \mathrm{~mm} / \mathrm{min}$.

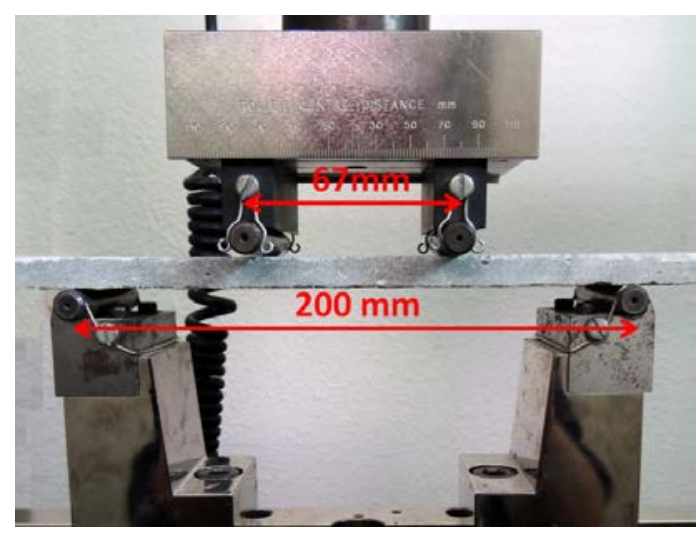

Figure 6. Mechanical test of GRC specimens. Four point bending test EN 1170-5

\subsubsection{Scanning electronic microscope (SEM) observations}

The microstructure evolution and the integrity of the fiber with ageing were studied by scanning electron microscopy (SEM, JEOL JSM6300). 


\section{$4 \quad$ Results and Discussion}

\subsection{Nonlinear Impact Resonant Acoustic Spectroscopy}

NIRAS measurement allows monitoring of a number of resonance frequencies and shift in these frequency values with increasing level of impact energy. The main advantage of obtaining the resonance frequencies by a hammer impact is that it excites several modes of vibration simultaneously since the impact has a wide range of frequencies. Figure 7 shows resonance frequencies for un-aged and aged (after 150 hours) specimens at ten different levels of impact energy for each NIRAS test. Three observations can be made from the spectra presented here. (i) In all cases it can be clearly seen that the resonance frequencies increase with the time of ageing. For example, the resonance frequency for F1FLEX increases from $750 \mathrm{~Hz}$ to $800 \mathrm{~Hz}$ (see Figure 7a). (ii) The gap between the frequency peaks changes with ageing (see Figure 7b); in Figure 7b peaks corresponding to F2FLEX and F1TOR are shown. The increase of frequency is higher for F1TOR than that for F2FLEX, and iii) the variation of the resonance frequency with the striking force amplitude is different for aged and un-aged specimens. 

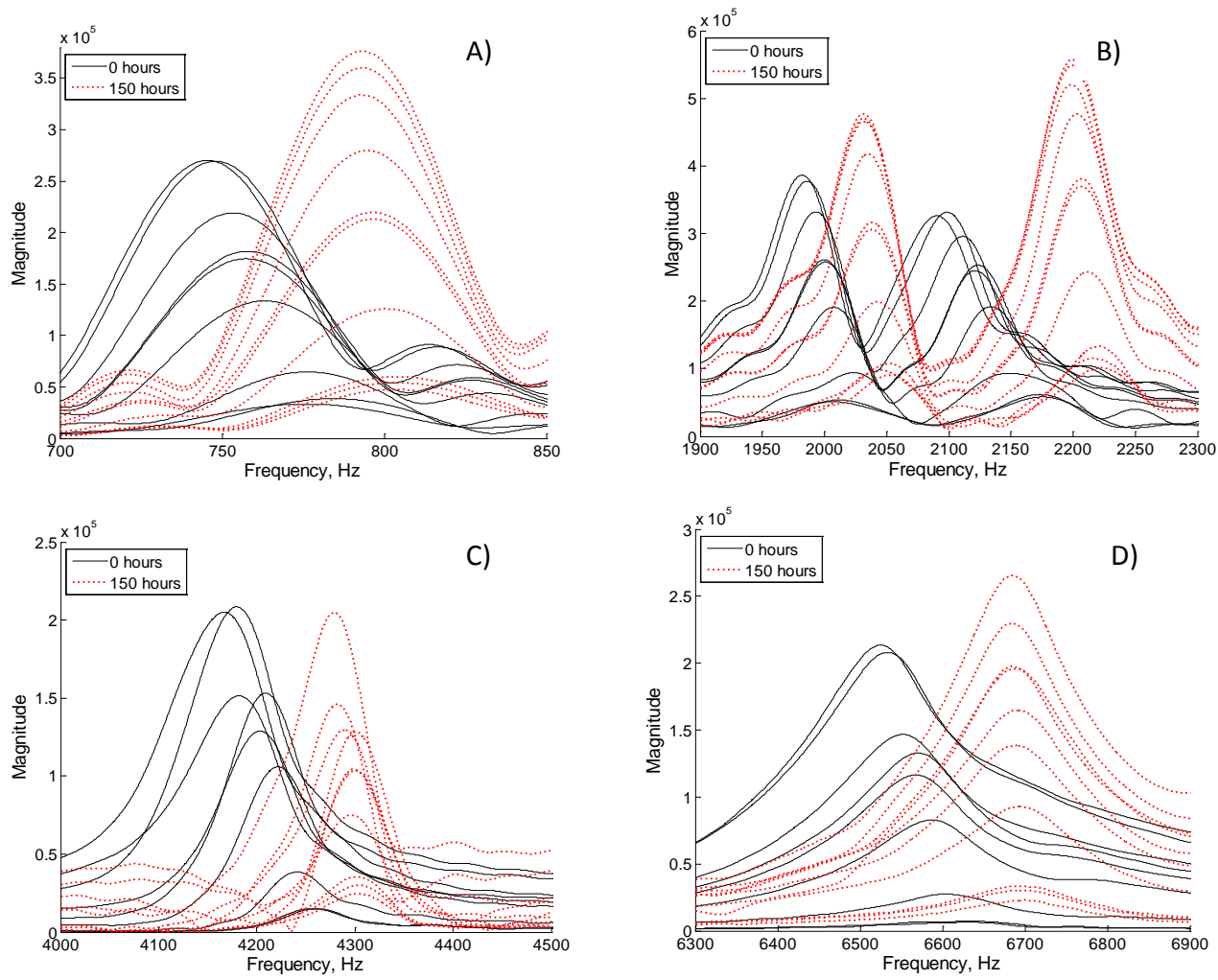

Figure 7. Resonance peaks for un-aged and aged specimens (i.e. 0 and 150 hours of accelerated ageing). A)

\section{F1FLEX, B) F1TOR and F2FLEX, C) F2TOR and D) F3TOR}

An Analysis of variance (ANOVA) was carried out taking every resonance frequency as the dependent variable (F1FLEX, F1TOR, F2FLEX, F2TOR, F3TOR) in order to observe the qualitative differences between different durations of ageing considered in this investigation. Slight deviations from hypothesis of homoscedasticity and normal distribution of the data as required for ANOVA were noted. Nevertheless the ANOVA is robust to such deviations [30]. The null hypothesis is that the mean values between ageing times remain the same while the alternative hypothesis is that there exists an ageing time that is statistically different with a significance level of 95\%. If the null hypothesis is rejected, the Least Significant Difference (LSD) intervals are computed for each treatment to determine for what ageing times the significant difference exists. 
Where $\overline{X_{i}}$ is the mean frequency peak to be investigated, $t_{g l r}^{0.95}$ is the Student's-t distribution, $M S_{r}$ is the mean square of residuals and $n$ is the number of observations. A total of 5 samples were tested at 5 ageing times 0 , 40, 80, 120 and 150 hours. The frequency spectrum was recorded at 10 different energy levels. Figure 7 shows the mean values and the 95\% LSD intervals for the identified frequency peaks. In all cases, the ANOVA rejects the null hypothesis of mean equivalency at different times of ageing $(\mathrm{p}<0.05)$. The identified resonant flexural modes F1FLEX, F2FLEX and torsional modes F1TOR, F2TOR, F3TOR show similar behavior.

While the flexural modes can better distinguish between un-aged and 40 hours long aged specimens in comparison to torsional modes, the torsional modes can differentiate better between the intermediate times of ageing (40, 80 and 120 hours). The natural frequencies of flexural (or bending) and torsional modes increase with time of ageing indicating an increase of stiffness of the material. This effect can be attributed to the combined effect of the evolution of the hydration products in the matrix and the degradation of the fibers in the cement matrix. 

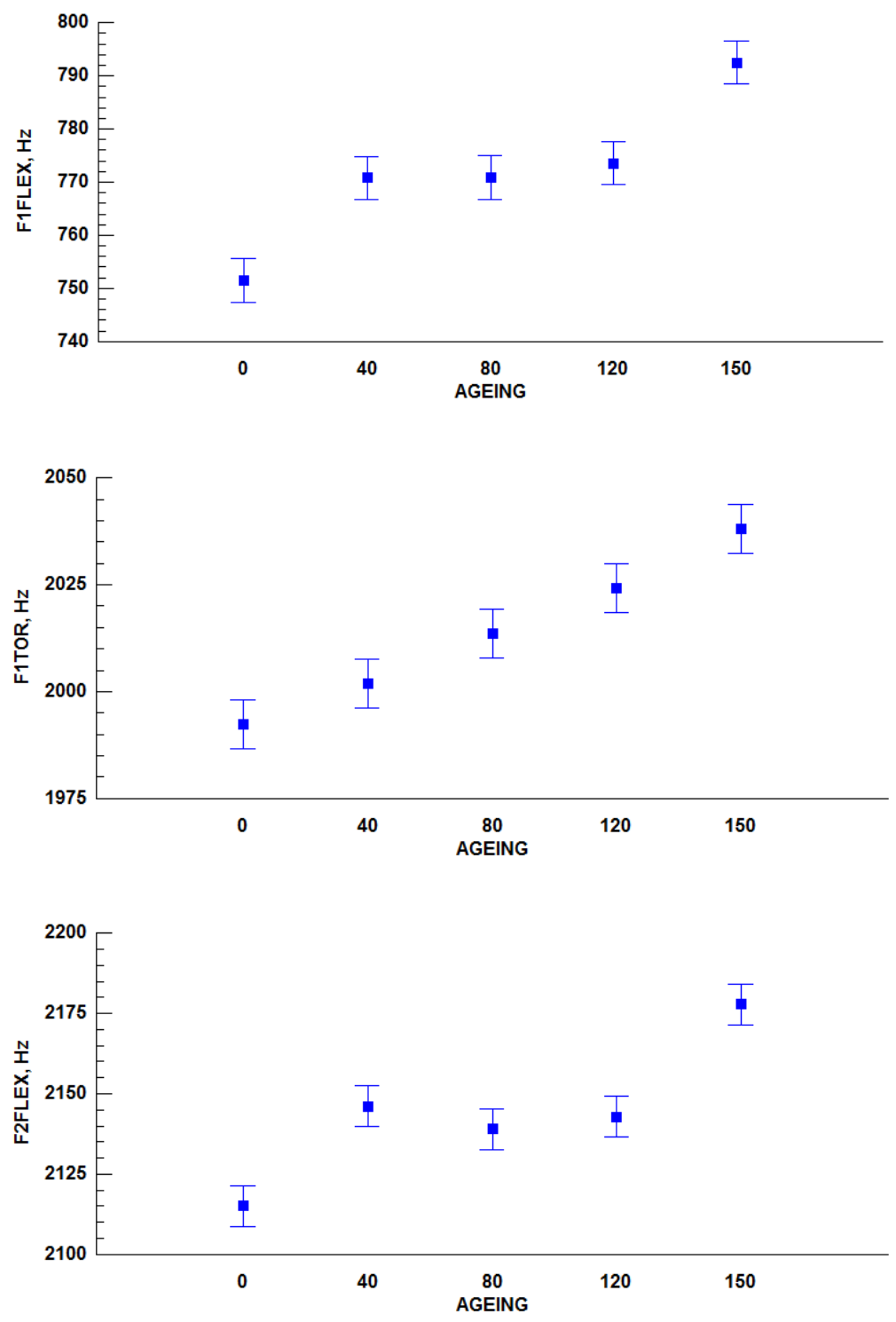

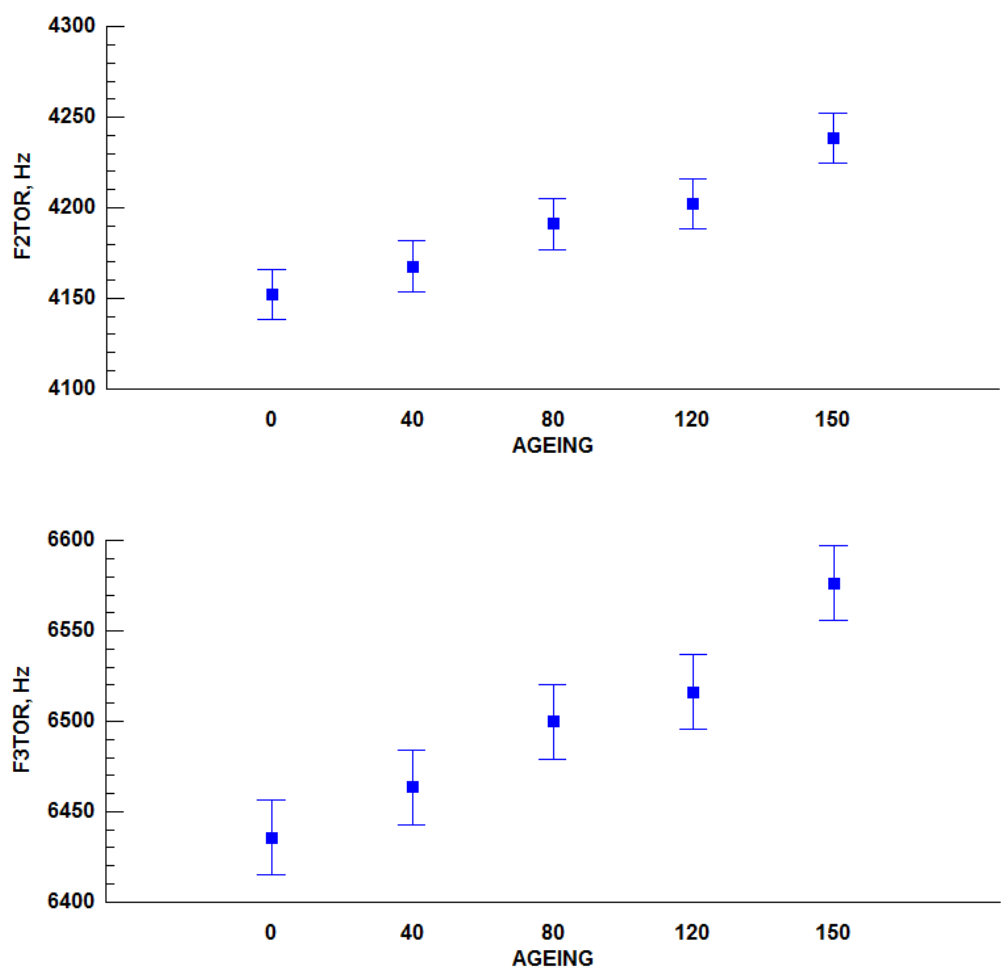

Figure 8. Mean and 95\% Least Significant Difference for the identified resonance frequencies.

The second aforementioned effect listed above is that the relative distances between the torsional and flexural peaks change with ageing as it can be seen in Figure 7b. The Poisson's ratio $v$, of a linear elastic isotropic material is a function of the Young's modulus $E$ and the shear modulus $G$ [31].

$v=\frac{E}{2 G}-1$

Since the Young's modulus $E$ is related to the flexural mode (F1FLEX) and the shear modulus $G$ affects the torsional mode (F1TOR) it can be shown that the Poisson's ratio is a function of the ratio of these two resonance frequencies F1TOR/F1FLEX [32]. Given that $E$ and $G$ are proportional to the squares of these frequencies (F1FLEX and F1TOR), the lower ratio F1TOR/F1FLEX indicates higher Poisson's ratio. Inverse problems will 
have to be solved to obtain the changes in the elastic properties with ageing. For facilitating the solution of the inverse problem an error function (4) that compares experimental and computed eigen frequencies, is used as dependent variable in a factorial $3^{2}$ while $E$ and $v$ are used as independent variables.

The error function is based on the root of the squared deviation between experimental and computed eigen frequencies of the first flexural mode plus the root squared deviation between the computed and experimental first torsional mode to first flexural ratio. The left squared deviation is related to the elastic modulus $E$ and the right term is related to the Poisson's ratio $v$.

$\operatorname{ERROR}_{i j}=\sqrt{(F 1 F L E X-C 1 F L E X)^{2}}+w \cdot \sqrt{\left(\frac{F 1 T O R}{F 1 F L E X}-\frac{C 1 T O R}{C 1 F L E X}\right)^{2}}$

Where C1FLEX and C1TOR are the computed resonance frequencies obtained from the FEM analysis for the first bending and torsional modes; F1FLEX and F1TOR are the experimental values of the resonance frequencies for the bending and torsional modes and $w$ is a weight factor whose value must be chosen in such a manner that the left and right terms of the above expression have the same order of magnitude. For our problem $w=100$. The working levels of the factorial $3^{2}$ design and their respective computed frequencies are listed in Table 1 . The optimal solution corresponds to the $E$ and $v$ values that minimize the error function.

Table 1. Values obtained by FEM analysis in the factorial design $3^{2}$

\begin{tabular}{|l|l|l|l|}
\hline E, GPa & $v$ & C1FLEX & C1TOR \\
\hline 26 & 0.12 & 685.87 & 1862.73 \\
\hline 32 & 0.12 & 760.91 & 2066.51 \\
\hline 38 & 0.12 & 829.18 & 2251.93 \\
\hline 26 & 0.2 & 686.13 & 1800.91 \\
\hline 32 & 0.2 & 761.20 & 1997.93 \\
\hline 38 & 0.2 & 829.49 & 2177.19 \\
\hline 26 & 0.28 & 686.53 & 1745.00 \\
\hline 32 & 0.28 & 761.64 & 1935.90 \\
\hline
\end{tabular}




\begin{tabular}{|l|l|l|l|}
\hline 38 & 0.28 & 829.98 & 2109.60 \\
\hline
\end{tabular}

The computed frequencies are compared with 250 observations (i.e. $\mathrm{j}=250$ ) for k number of peaks identified for a given time of ageing by means of the error function. The number of resonance modes used is $2(\mathrm{i} . e . \mathrm{k}=2)$ since the error function is based on only the first two eigen frequencies, first flexural and first torsional modes. The process is repeated for all times of ageing. A schematic diagram describing the process is shown in Figure 9.
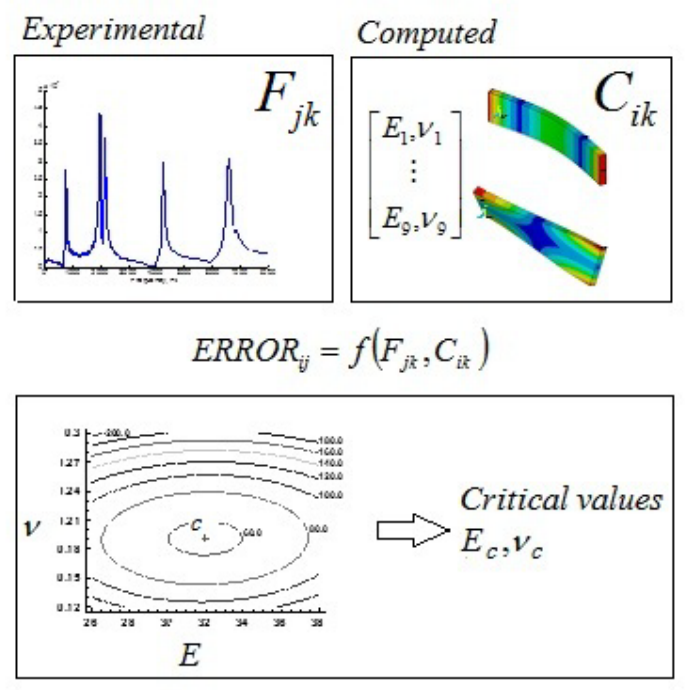

Figure 9. Schematic diagram of the process to obtain $E$ and $v$ values by minimizing the Error function in a $3^{2}$ factorial design.

Figure 10 shows the response surface obtained for 0 and 150 hours of ageing. From this figure it can be concluded that the Elastic modulus and the Poisson's ratio increase with ageing. Table 2 lists the results for various times of ageing studied here. Note that the obtained adjusted $\mathrm{R}^{2}$ increases with ageing. It can be due to the fact that the aged GRC is closer to a linear isotropic material compared to the un-aged GRC. From this table one can see that the predicted values of $E$ and $v$ increase as the ageing time increases. Closeness of $E$ and $v$ values obtained from two different techniques increases the confidence on our experimental measurements. 

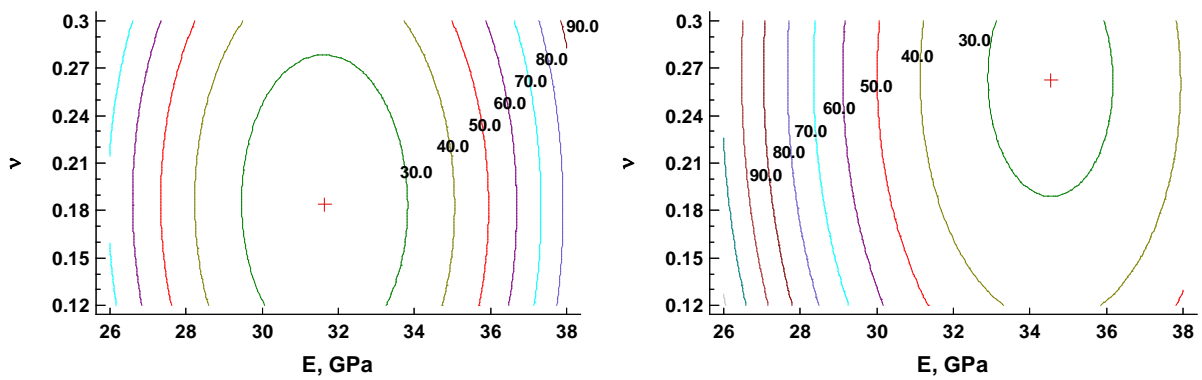

Figure 10. Surface response for the error function at 0 hours of ageing (left) and 150 hours of ageing (right).

$$
\frac{E R R O R_{0 h}=1510.6-92.13 E-310.66 v+1.45 E^{2}+0.76 E v+777.86 v^{2}}{E R R O R_{150 h}=1415.57-78.03 E-315.04 v+1.13 E^{2}+0.74 E v+550.93 v^{2}}
$$

Table 2. ANOVA table for the response surfaces of the error function - predicted $\mathrm{E}$ and $v$ values and comparison

\begin{tabular}{|c|c|c|c|c|c|c|c|c|c|c|}
\hline \multirow{2}{*}{ Ageing } & \multicolumn{5}{|c|}{ p-value } & \multirow[t]{2}{*}{$\mathrm{R}^{2}$} & \multicolumn{2}{|c|}{ Predicted values } & \multirow[b]{2}{*}{ Ed ASTM } & \multirow[b]{2}{*}{$v \mathrm{~d}$ ASTM } \\
\hline & $\mathrm{E}$ & $v$ & $\mathrm{E}^{2}$ & $v^{2}$ & $E \cdot v$ & & $\mathrm{E}_{\mathrm{c}}$ & $v_{c}$ & & \\
\hline 0 hours & 0.00 & 0.15 & 0.00 & 0.04 & 0.82 & 53.39 & 31.64 & 0.18 & 31.45 & 0.16 \\
\hline 40 hours & 0.00 & 0.01 & 0.00 & 0.04 & 0.81 & 58.59 & 32.79 & 0.23 & 32.95 & 0.21 \\
\hline 80 hours & 0.00 & 0.07 & 0.00 & 0.00 & 0.74 & 78.66 & 32.68 & 0.21 & 33.09 & 0.20 \\
\hline 120 hours & 0.00 & 0.24 & 0.00 & 0.00 & 0.76 & 72.26 & 33.44 & 0.22 & 33.43 & 0.20 \\
\hline 150 hours & 0.00 & 0.00 & 0.00 & 0.04 & 0.76 & 81.07 & 34.50 & 0.26 & 34.99 & 0.24 \\
\hline
\end{tabular}
with transverse dynamic modulus of elasticity and dynamic Poisson’s ratio as prescribed in ASTM C-215. 
During the hydration of portland cement, the hydration products are formed as a coherent matrix enclosing remnants of anhydrous cement [33]. A major quantity of anhydrous cement is expected for low water to cement ratio, $\mathrm{w} / \mathrm{c}=0.35$ in this study. Therefore, a densification of the matrix takes place with ageing and as a consequence an increase of dynamic modulus can be expected. In addition, when chemical degradation of the glass fibers take place with ageing, the fibers are partially combined with the hydration products in the matrix, contributing in this manner to the overall densification. Results reported by Payá et al. [7] on 40x40x160 mm GRC samples show that ageing increases the compressive strength as a result of the completion of the hydration and the pozzolanic reaction.

It should be noted that the resonance frequencies vary noticeably with increasing energy of impact for un-aged specimens but this variation is very small for fully aged specimens. The resonance frequency shift was assessed for every peak using equation (2). Since the amplitude is proportional to the strain amplitude $(\Delta \varepsilon)$, the hysteretic parameter $\alpha$ can be estimated from this amplitude. Figure 11 shows the F1FLEX peaks identified at different energy levels and corresponding $\alpha$ calculations (HYST1FLEX).

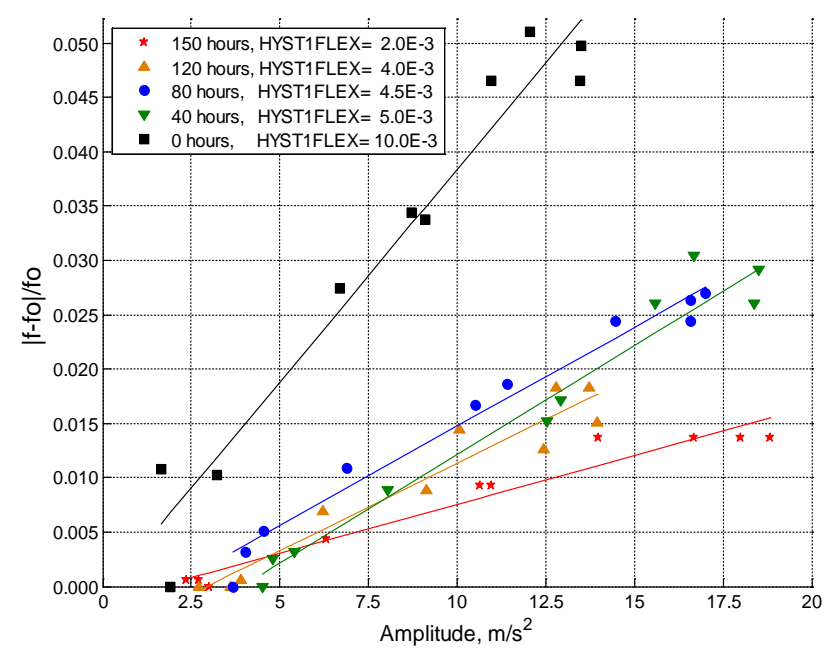

Figure 11. Resonance Frequency shift for the first flexural mode (F1FLEX) as a function of the impact energy level for different ageing times and hysteretic parameter computation HYST1FLEX 
In a similar analysis conducted on the resonance frequencies, an ANOVA was performed on the obtained hysteretic parameter for every resonance peak (HYST1FLEX, HYST1TOR, HYST2FLEX, HYST2TOR, HYST3TOR). Figure 12 shows the mean and 95\% LSD intervals for every time of ageing. It is found that the hysteretic parameter computed for every resonance frequency decreases with ageing. With the exception of the hysteretic parameter for the third torsional frequency (HYST3TOR), it is found that the hysteretic nonlinear parameters can only distinguish between un-aged and aged specimens but they are not very sensitive to the variations in the time of ageing (40, 80, 120 or 150$)$. 

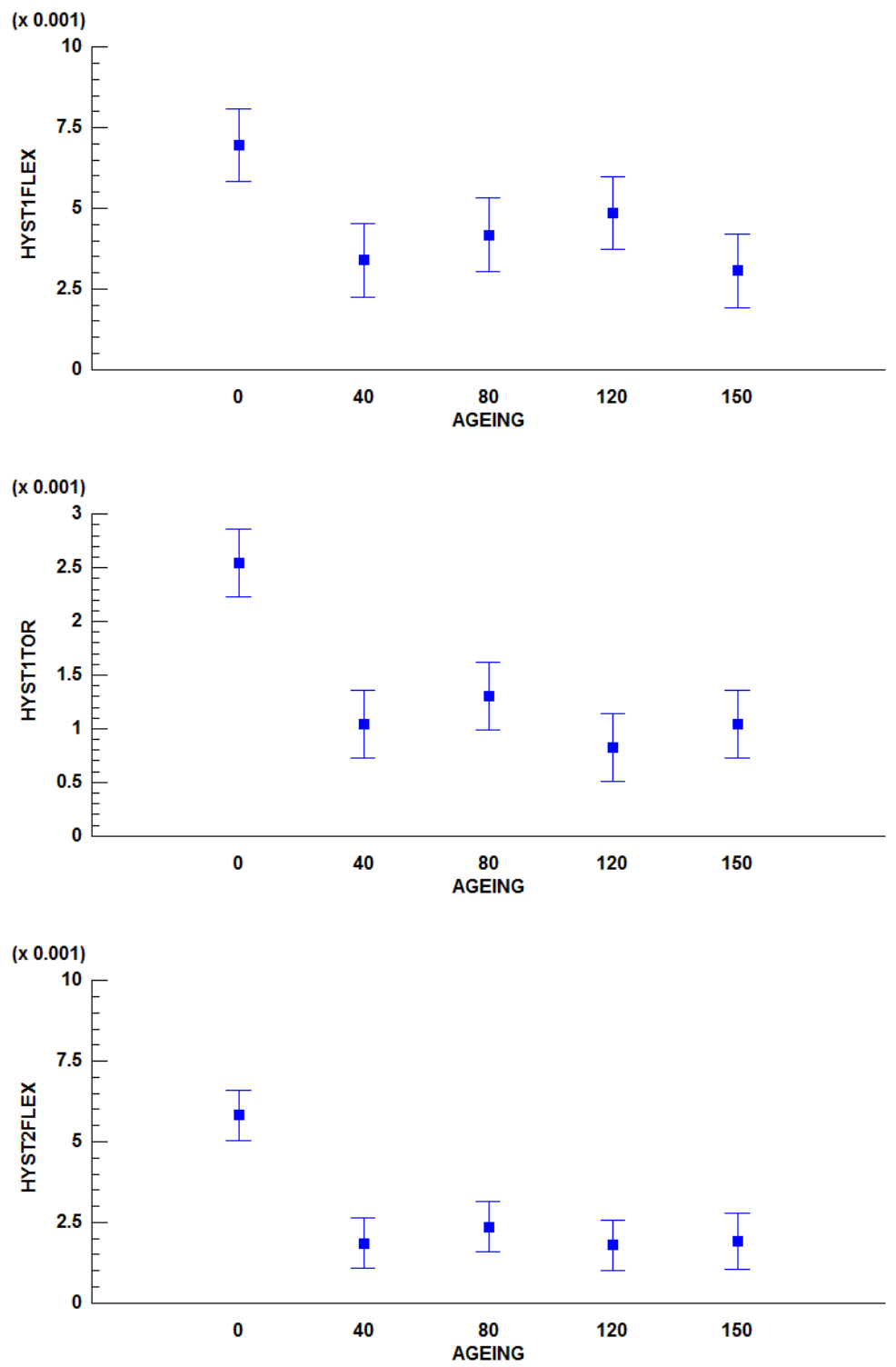

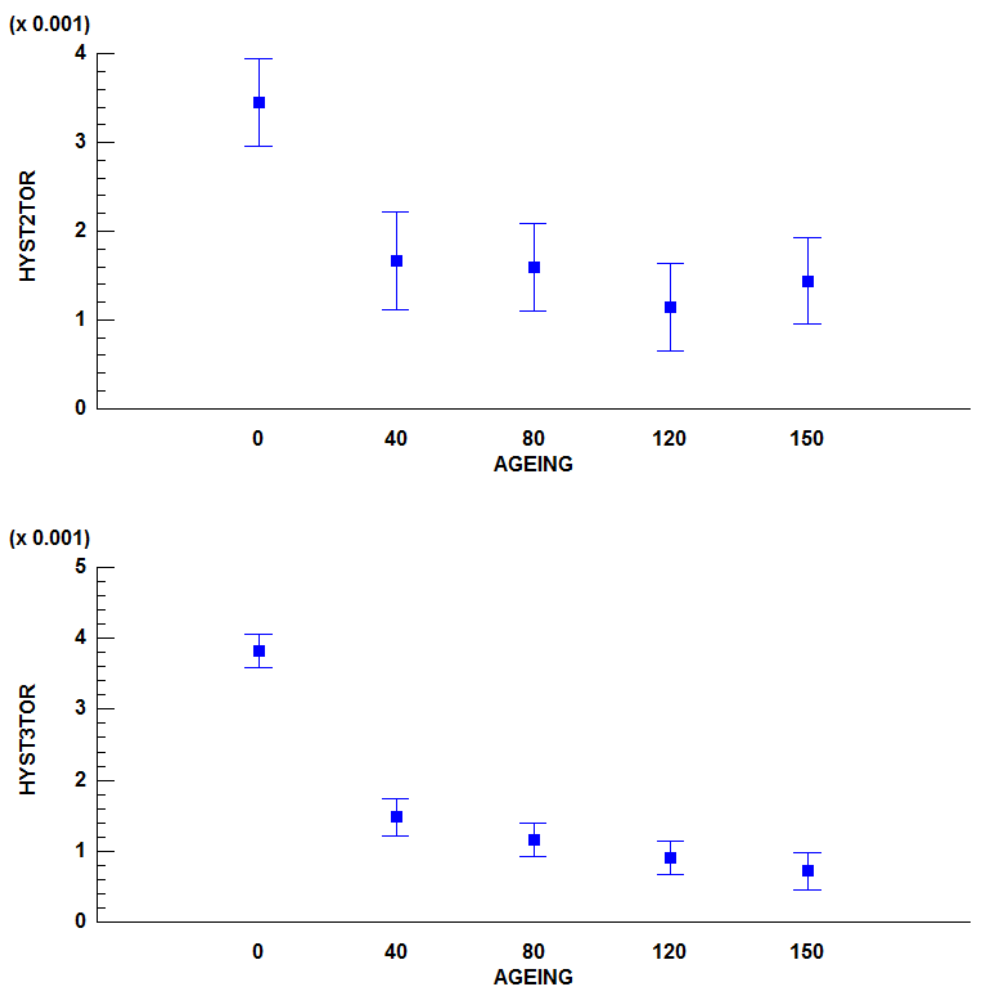

Figure 12. Mean and 95\% Least Significant Difference for the computed hysteretic parameters for each frequency identified.

It can be clearly seen that the LSD are much shorter for the third torsional peak. The monotonic variation of the hysteretic parameter with ageing is observed at higher frequency (HYST3TOR) when the hysteretic parameter can be estimated more accurately (Figure 13). 


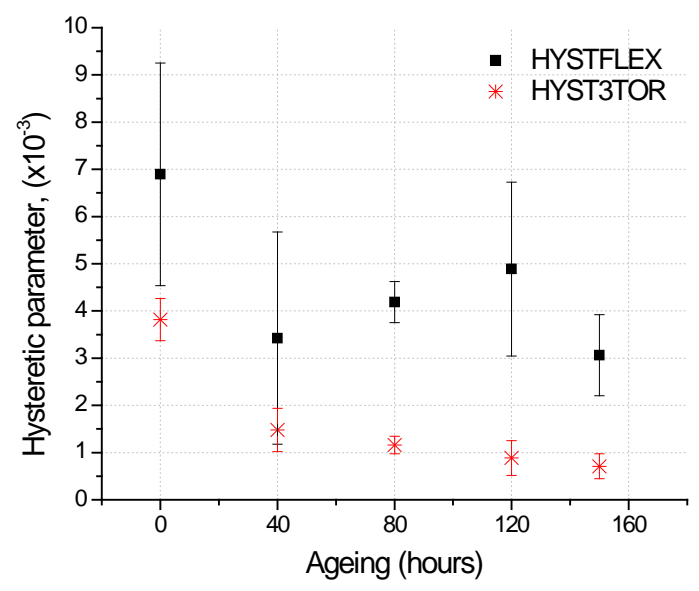

Figure 13. Hysteretic parameter obtained for flexural and torsional modes for different durations of ageing

Nonlinear dynamic hysteretic behavior is related to the amount of mesoscopic defects like pores, cracks, clapping contacts or rough contacts between neighboring grains [15]. The incorporation of glass fiber in cement based materials represents a mesoscopic defect itself. Zhu and Bartos [34] demonstrated by the microindentation technique that the interfacial bond of individual filaments is weaker in the fiber bundle than that at the bundle matrix interface. Similar findings were reported by Purnell et al. [35] who studied the interface transition zone by petrographical analysis. After ageing, the inner microstructure within the strand becomes denser and stronger. These findings are in agreement with the measurement of the nonlinear hysteretic parameter $\alpha$. Since the mesoscopic defects created by the presence of the fibers activate fast dynamic effect in resonance tests, it is mitigated with ageing. Therefore, the precipitation of dense hydration products around the fibers improves the bonding between matrix and fiber. This phenomenon is detected nondestructively by NIRAS measurements.

\subsection{Mechanical properties}

The mechanical properties were evaluated for two aged and two un-aged specimens. Figure 14 shows the loaddisplacement curves for these four specimens when they were subjected to displacement control loading in 4-point bending configuration. 


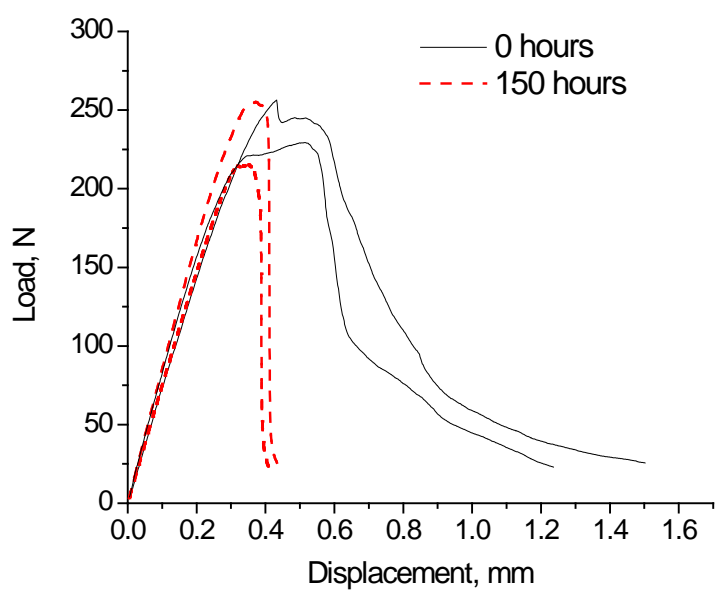

Figure 14. Force-displacement curves for GRC specimens - un-aged (continuous lines) and aged for 150 hours (dashed lines).

$$
\begin{aligned}
& \sigma_{M O R}=\frac{F_{M O R} \cdot L}{b \cdot d^{2}} \\
& \varepsilon_{M O R}=\frac{27}{5} \cdot \frac{\Delta_{M O R} \cdot d}{L^{2}}
\end{aligned}
$$

The mechanical properties listed in Table 3 are calculated from equations (5), (6) and from the load-displacement curves shown in Figure 14.. These results confirm the findings reported by others that GRC becomes weaker with time [1-2]. Although there is no important difference between flexural strength and static modulus of aged and unaged samples, the most interesting observations are the toughness decreasing with ageing and the decrease of strain at maximum load $\left(\varepsilon_{\mathrm{MOR}}\right)$. The fracture behavior of fiber reinforced cement-based materials can be described by the bridged crack model [36, 37] and the toughening mechanisms of fiber reinforced cement-based materials are based on fiber/matrix interactions. These mechanisms include interfacial debonding, frictional sliding and inclined angle effects. The bridging effect of the fibers restricting the opening and propagation of microcracks ends when the fibers rupture in the case of brittle fibers like carbon or glass [38]. Despite the low toughness obtained for aged GRC 
samples, this value is still higher than the unreinforced cement-based material, since we still obtain some additional deformation because of the bridging fibers beyond the proportionality limit.

Table 3. Mechanical properties for un-aged and aged specimens

\begin{tabular}{|l|l|l|l|l|l|}
\hline Sample & AGEING & $\sigma_{\mathrm{MOR}}$ & $\varepsilon_{\mathrm{MOR}}$ & Static Modulus & Work of fracture \\
$($ hours $)$ & $(\mathrm{MPa})$ & $\left(10^{-4} \mathrm{~mm} / \mathrm{mm}\right)$ & $(\mathrm{GPa})$ & $\mathrm{N} \cdot \mathrm{mm}$ at $10 \%$ of $\sigma_{\mathrm{MOR}}$ \\
\hline U1 & 0 & 10.25 & 5.84 & 21.27 & 169.49 \\
\hline U2 & 0 & 9.17 & 6.95 & 24.29 & 139.24 \\
\hline A1 & 150 & 8.61 & 4.73 & 22.08 & 52.16 \\
\hline A2 & 150 & 10.21 & 5.00 & 25.21 & 65.59 \\
\hline
\end{tabular}

\subsection{Ultrasonic Guided Waves}

It is then investigated if the nonlinear behavior in GRC can be identified using ultrasonic guided waves. Aged and un-aged specimens were tested using ultrasonic guided waves to reconfirm the conclusion of NIRAS that ageing makes the GRC specimens more linear. Three un-aged and three aged specimens were inspected and typical spectral plots of un-aged and aged specimens are shown in Figure 15. 


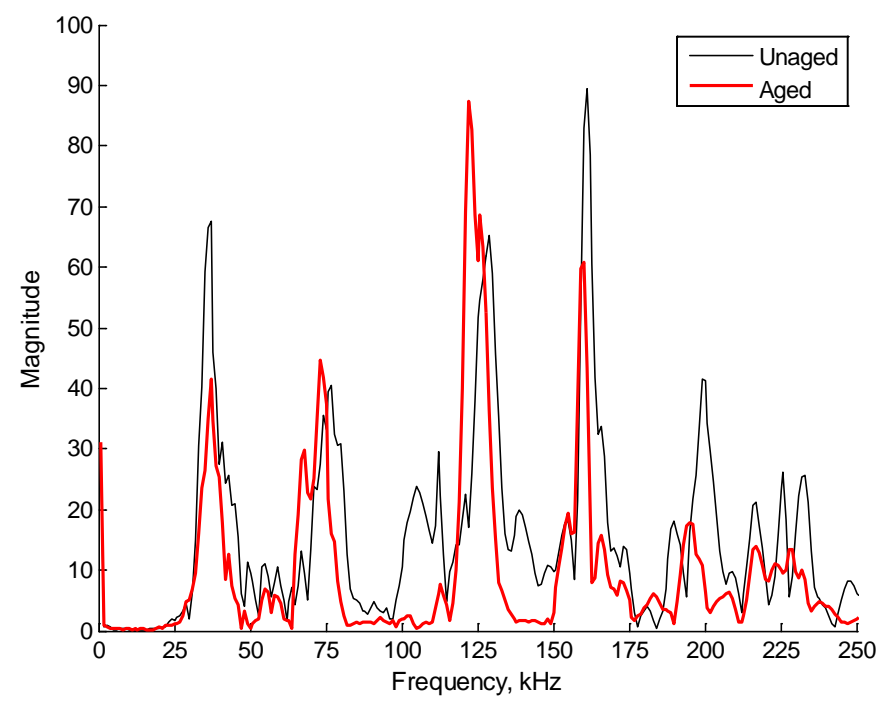

Figure 15. Spectral plots of recorded time histories obtained by FFT (Fast Fourier Transform)

Four most dominant peaks between 25 and $175 \mathrm{kHz}$ and two other relatively strong peaks between 175 and $250 \mathrm{kHz}$ are present in both aged and un-aged specimens' spectra. These peaks may be generated by different guided wave modes (Lamb wave modes) propagating through the plate, standing wave modes or simply the resonance modes of the specimen. To investigate if these are propagating wave modes or simply the resonance modes one can conduct the experiment on another plate specimen having the same thickness but different length and width. If the peak positions do not change then they must correspond to the propagating Lamb wave modes, otherwise those are generated by different resonance modes or standing wave modes since the frequencies of the resonance modes are functions of the length and width of the plate as well. However, our interest is not in these dominant peaks but in the weak peaks in the neighborhood of the strong peaks that are generated by the material nonlinearity and/or the anomalies in the material. The imperfect interface between the fibers and the matrix can give rise to friction between glass fibers and cement matrix causing nonlinear behavior of the material. However, the question remains whether in absence of a low frequency high amplitude modulation signal the material can show nonlinear behavior. Van Den Abeele et al. [39] have shown that in a nonlinear material the sideband energy for the high frequency (120$134 \mathrm{kHz})$ bulk waves increases with the strength of the low frequency (1-20 kHz) modulation signal. However, 
even when the modulation signal has almost zero strength the sideband energy for the nonlinear material is significant and measurable. Therefore, in absence of the modulation signal also the nonlinear behavior of the material is expected and it can be monitored by the sideband energy. These smaller peaks can be generated by multiple scattering of the waves by anomalies (glass fibers) in the plate as well. Therefore, it can be safely stated that the occurrence of minor peaks is an indication of the presence of anomalies in the material that causes the deviation of the material from an ideal homogeneous linear elastic state. Our investigation focuses on these smaller or minor peaks instead of the dominant or major peaks. From Figures 15 and 16 one can clearly see that the un-aged specimens show greater number and relatively stronger minor peaks compared to the aged specimens. Therefore the un-aged specimens are more non-linear than the aged specimens as was observed by NIRAS.

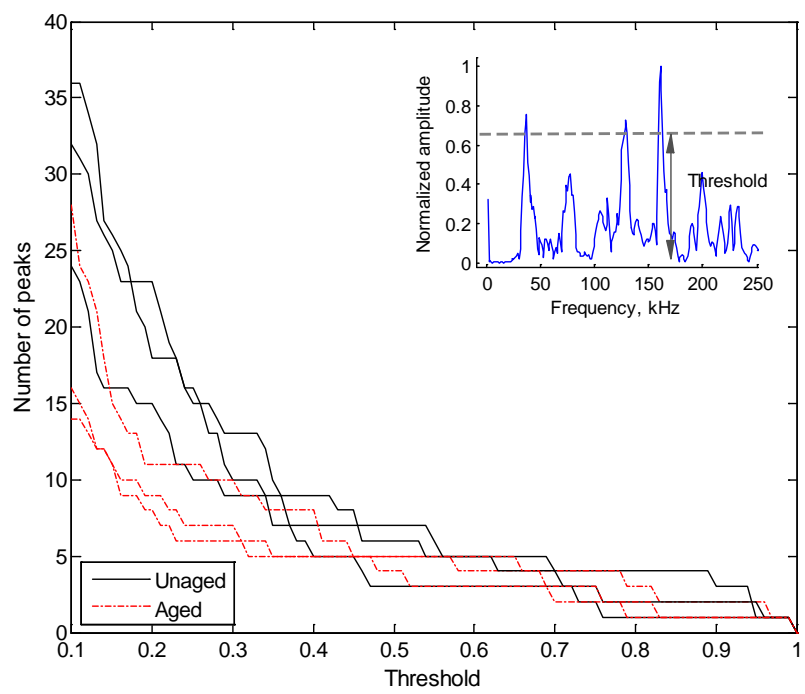

Figure 16. Peak values (above the threshold value) for the spectral plots of Figure 12 are shown in this figure.

If the number of peaks above a pre-set threshold value, plotted in Figure 16, is an indirect measure of the material nonlinearity then in a non-linear material this value should increase with increasing amplitude of the driving voltage. This is because with increasing driving voltage as the amplitude of the propagating wave increases the energy loss due to friction at the fiber-matrix interfaces or micro-crack surfaces in contact should increase resulting more nonlinear behavior in the material. Figure 17 shows that, as expected, the number of peaks above the threshold 
value increases with the driving voltage for both un-aged and aged specimens. However, for the un-aged specimen this increase is much more than that for the aged specimen. For example note that when the driving voltage is increased from $200 \mathrm{~V}$ to $600 \mathrm{~V}$ the curves for the aged specimen do not change significantly but for the un-aged specimen there is a big jump indicating strong nonlinear behavior for the un-aged specimen.

One shortcoming of any vibration based technique including NIRAS is that the specimen is susceptible to surface damage due to repeated hammer strikes at the same spot with increasing intensity. This shortcoming is absent in the UGW testing. No new damage is generated in the specimen from the UGW test since the excitation energy level is much smaller in this case and yet it is sensitive to the deviation of the material from its linear elastic homogeneous state, as seen here.

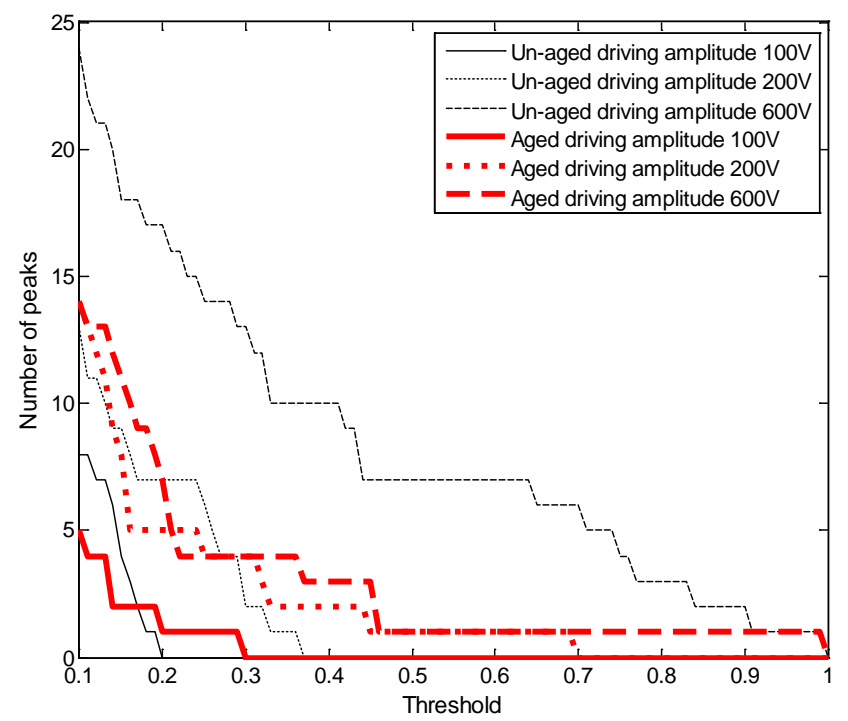

Figure 17. Number of peaks above the preset threshold for different driving voltage values

\subsection{SEM observations}

The fibers in the un-aged matrix are shown in Figure 18 (a and b images). In Figure 18a, it can be seen that the multifilament fiber is surrounded by cement hydrated products. These products do not completely fill the voids adjacent to the filaments. Figure 18b shows a typical surface of the filament in which damage is not evident showing smooth surface of the filament and compact hydration products surrounding it. Figure 18c shows that after ageing the multifilament structure is maintained, and more cement hydration products appear near the filaments. The most noticeable change is the formation of unevenly distributed small spots (diameter $<1 \mu \mathrm{m}$ ) on the surface of the 
filament (Figure 18d). Sometimes several spots appear very close to one another, forming relatively bigger flaws, as shown in Figure 18d. This figure shows that the ageing at $65^{\circ} \mathrm{C}$ produced a severe level of corrosion on the surface of the filaments, despite relatively short ageing time (150 hours). Similar high degree of corrosion in filaments under accelerated ageing environment was reported by Litherland, Oakley and Proctor [13]. Such accelerated ageing is needed to predict the long term strength of GRC composites. It has been reported in the literature [13] that ageing temperatures higher than $50^{\circ} \mathrm{C}$ produce significant reduction in flexural strength in less than 10 days because the corrosion rate is high.

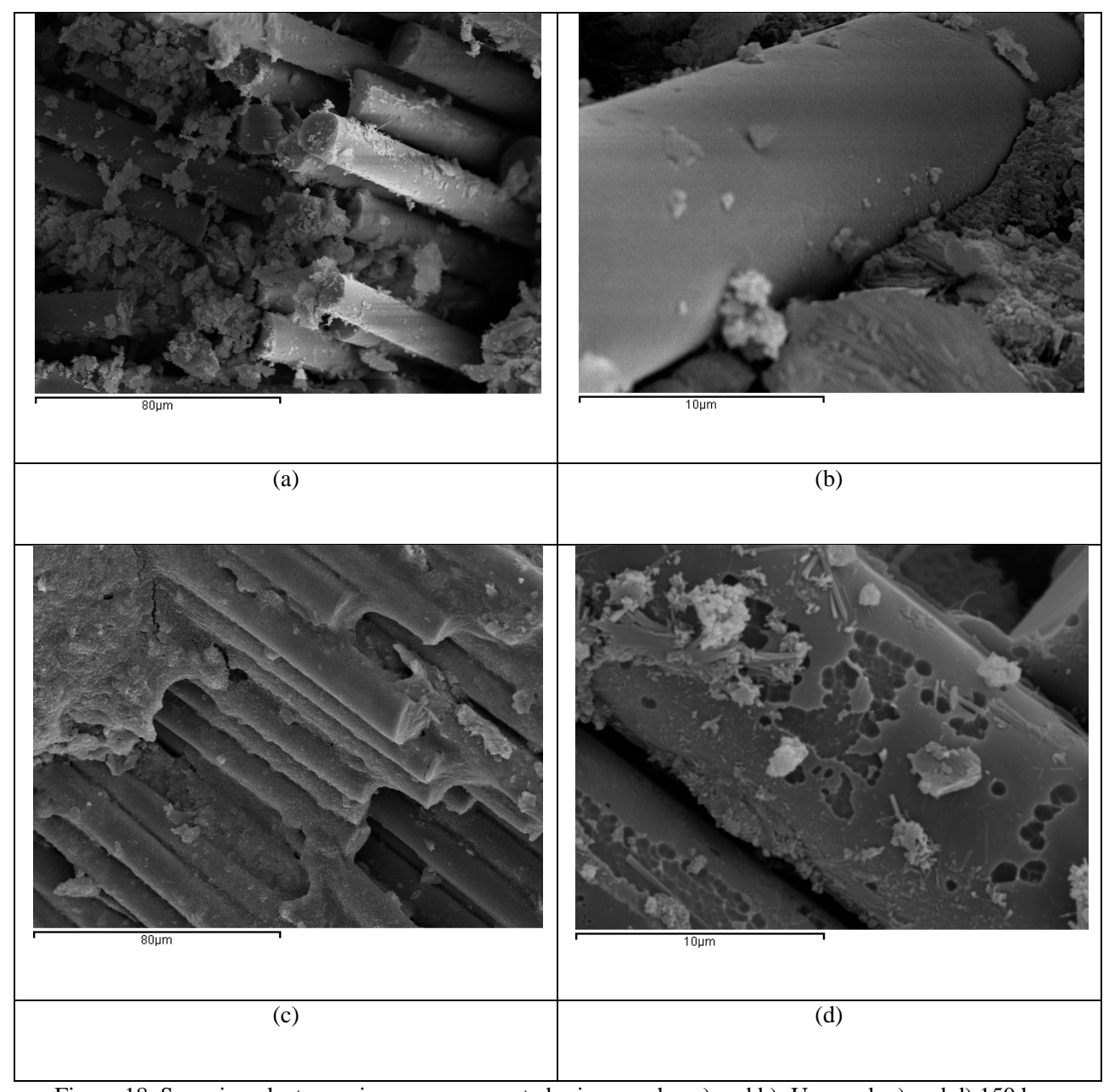

Figure 18. Scanning electron microscope generated micrographs: a) and b): Un-aged; c) and d) 150 hours aged. 


\section{Conclussions}

Ageing of glass fiber reinforced cement is investigated. As expected the ageing from the hot water immersion deteriorates the glass fibers; it is confirmed by the scanning electron microscopy (SEM) observations. As a result of this deterioration the toughness of the specimen gained from the presence of the fibers is lost when the specimen is aged. The decrease of toughness with ageing is confirmed by the mechanical testing using universal testing machine.

However, in contrast to the common wisdom it is observed in this investigation that as the material deteriorates it becomes more linear instead of being more non-linear that is observed during other types of material degradation such as under fatigue loading. For GRC specimens the ageing from the hot water immersion deteriorates the fibers and thus makes the material weaker but more linear. Two different sets of nondestructive tests - NIRAS and UGW confirmed that the material becomes more linear with ageing from the hot water immersion.

NIRAS measurements allow us to monitor several resonant modes simultaneously allowing a complete overview of the mechanical integrity of the material. The dynamic signatures of aged GRC specimens were closely studied and the following observations were made.

i) With ageing an increase in the natural frequency of the flexural and torsional modes were observed. The ANOVA results could distinguish between different times of ageing. The flexural modes can detect accurately the shorter time of ageing while the torsional modes can distinguish between different times of ageing.

ii) The gap between the resonance peaks change with ageing.

iii) The first two observations (i and ii) indicate a change in Young's modulus, Shear modulus and consequently Poisson's ratio. An Inverse Problem was designed to obtain the elastic properties (Young's modulus and Poisson's ratio) of the specimens by mixing a factorial design of experiments and Finite element method. From this analysis an increase of the Young's modulus and the Poisson's ratio was observed with ageing.

iv) The hysteretic nonlinear parameters identified for every peak is a sensitive indicator of the degradation of fibers with ageing. The hysteretic parameter computed from the highest frequency was identified. It was observed that this parameter could be computed more accurately from the third torsional mode than other resonance peaks at lower frequencies. 
NIRAS test is suitable for laboratory inspection of specimens and it can provide reliable information about GRC ageing, while for UGW, since the only requirement is that the wave must propagate through a waveguide, it is easy to apply this technique for in-situ testing of plate, and shell type structures.

\section{Acknowledgements}

The authors want to acknowledge the financial support of the Ministerio de Ciencia e Innovación MICINN, Spain, and FEDER funding (Ondacem Project: BIA 2010-19933) and BES-2011-044624. Also thanks to PAID-02-11 Program from Universitat Politècnica de Valencia.

The authors would also like to acknowledge the contributions of José Benedito (Universitat Politècnica de Valencia) and John S. Popovics (University of Illinois at Urbana-Champaign) to this work.

\section{References}

1. Bentur A, Mindess S. Fibre Reinforced Cementitious Composites, 2nd ed. New York: Taylor and Francis; 2007.

2. Purnell P, Short NR, Page CL. A static fatigue model for the durability of glass fibre reinforced cement. J Mater Sci 2001; 36 (22): 5385-5390.

3. Ferreira JG, Branco FA. Structural application of GRC in telecommunication towers. Constr Build Mater 2007; 21 (1): 19-28.

4. Bentur A, Ben-Bassat M, Schneider D. Durability of Glass-Fiber-Reinforced Cements with Different Alkali-Resistant Glass Fibers. J Am Ceram Soc, 68(4), 203-208 (1985).

5. Cheng J, Liang W, Hu Y, Chen Q, Frischat GH. Development of a New Alkali Resistant Coating. J SolGel Sci Tech, 27(3), 309-313 (2003).

6. Liang W, Cheng J, Hu Y, Luo H. Improved properties of GRC composites using commercial E-glass fibers with new coatings. Mater Res Bull, 37(4), 641-646 (2002).

7. Payá J, Bonilla M, Borrachero MV, Monzó J, Peris-Mora E, Lalinde LF. Reusing fly ash in glass fibre reinforced cement: A new generation of high-quality GRC composites. Waste Manag, 27(10), 1416-1421 (2007). 
8. Zhang Y, Sun W, Shang L, Pan G. The effect of high content of fly ash on the properties of glass fiber reinforced cementitious composites. Cem Concr Res, 27(12), 1885-1891 (1997).

9. Purnell P, Short N, Page C. Super-critical carbonation of glass-fibre reinforced cement. Part 1: mechanical testing and chemical analysis. Compos Part A: Appl Sci Manuf, 32(12), 1777-1787 (2001).

10. EN 1170-8:2008. Test method for glass-fibre reinforced cement. Cyclic weathering type test.

11. Purnell P. Interpretation of climatic temperature variations for accelerated ageing models. J Mater Sci 2004; 39 (1): 113-118.

12. Enfedaque A, Sánchez Paradela L, Sánchez-Gálvez V. An alternative methodology to predict aging effects on the mechanical properties of glass fiber reinforced cements (GRC). Constr Build Mater 2012; 27 (1): 425-431.

13. Litherland KL, Maguire P, Proctor BA. A test method for the strength of glass fibres in cement. Int J Cem Compos Light Concr 1984; 6 (1): 39-45.

14. Itterbeeck P, Cuypers H, Orlowsky J, Wastiels J. Evaluation of the strand in cement (SIC) test for GRCs with improved durability. Mater Struct 2007; 41 (6): 1109-1116.

15. Guyer RA, Johnson PA. Nonlinear mesoscopic elasticity: evidence for a new class of materials. Phys Today 1999; 52: 30.

16. Johnson PA. Nonequilibrium Nonlinear Dynamics in Solids: State of the Art. In: Delsanto PP ed. Universality of Nonclassical Nonlinearity, New York: Springer; 2006, p. 49-69.

17. Guyer RA, McCall KR, Boitnott GN. Hysteresis, Discrete Memory, and Nonlinear Wave Propagation in Rock: A New Paradigm. Phys Rev Lett 1995; 74 (17): 3491-3494.

18. Mayergoyz ID. Mathematical models of hysteresis and their applications. New York: Academic Press; 2003.

19. Van Den Abeele KEA, Carmeliet J, Ten Cate JA, Johnson PA. Nonlinear Elastic Wave Spectroscopy (NEWS) Techniques to Discern Material Damage, Part II: Single-Mode Nonlinear Resonance Acoustic Spectroscopy. Res Nondestruct Eval 2000; 12 (1): 31-42.

20. Chen J, Jayapalan AR, Kim JY, Kurtis KE, Jacobs LJ. Rapid evaluation of alkali-silica reactivity of aggregates using a nonlinear resonance spectroscopy technique. Cem Concr Res 2010; 40 (6): 914-923. 
21. Leśnicki KJ, Kim JY, Kurtis KE, Jacobs LJ. Characterization of ASR damage in concrete using nonlinear impact resonance acoustic spectroscopy technique. NDT \& E Int 2011; 44 (8): 721-727.

22. Bouchaala F, Payan C, Garnier V, Balayssac JP. Carbonation assessment in concrete by nonlinear ultrasound. Cem Concr Res 2011; 41 (5): 557-559.

23. Eiras JN, Popovics JS, Borrachero MV, Monzó J, Payá J. Nonlinear Impact Resonant Acoustic Spectroscopy to discern mechanical damage in cement based materials. 15th International Conference on Experimental Mechanics, 2012, Porto (Portugal).

24. Kundu T. Ultrasonic Nondestructive Evaluation: Engineering and Biological Material Characterization. Boca Raton: CRC Press; 2004.

25. Kundu T. Ultrasonic and Electromagnetic NDE for Structure and Material Characterization - Engineering and Biomedical Applications. Boca Raton: CRC Press; 2012.

26. Dutta D, Sohn H, Harries KA, Rizzo P. A Nonlinear Acoustic Technique for Crack Detection in Metallic Structures. Struct Health Monit 2009; 8 (3): 251-262.

27. Aymerich F, Staszewski WJ. Impact damage detection in composite laminates using nonlinear acoustics. Compos Part A: Appl Sci Manuf 2010; 41 (9): 1084-1092.

28. EN 1170-1:1998. Precast concrete products. Test method for glass-fibre reinforced cement. Measuring the consistency of the matrix, "Slump test” method

29. EN 1170-5:1998. Precast concrete products. Test method for glass-fibre reinforced cement. Measuring bending strength, “complete bending test” method.

30. Romero R, Zúnica LR. Métodos Estadísticos en Ingeniería. Valencia: Universitat Politècnica València; 2005.

31. Kundu T. Fundamentals of Fracture Mechanics. Boca Raton: CRC Press; 2008

32. ASTM C 215:08. Standard Test Method for Fundamental Transverse, Longitudinal, and Torsional Frequencies of Concrete Specimens.

33. Hewlett PC. Lea’s Chemistry of Cement and Concrete. 4th ed. Oxford: Butterworth-Heinemann; 2003.

34. Zhu W, Bartos PJM. Assessment of interfacial microstructure and bond properties in aged GRC using a novel microindentation method. Cem Concr Res 1997; 27 (11): 1701-1711. 
35. Purnell P, Buchanan AJ, Short NR, Page CL, Majumdar AJ. Determination of bond strength in glass fibre reinforced cement using petrography and image analysis. J Mater Sci 2000; 35 (18): 4653-4659.

36. Visalvanich K, Naaman AE. Fracture Model for Fiber Reinforced Concrete. ACI J Proceed 1983; 80 (2): 128-138.

37. Kundu T, Jang HS, Cha YH, Desai CS. A simple model to predict the effect of volume fraction, diameter, Con formato: Inglés (Estados Unidos) and length of fibers on strength variation of fiber reinforced brittle matrix composites, Int. J. for Numerical and Analytical Methods in Geomechanics 2000; 24: 655-673.

38. Li VC, Maalej M, Toughening in Cement Based Composites. Part II: Fiber Reinforced Composites. Cem Concr Compos 1996; 18: 239-249.

39. Van Den Abeele KEA, Johnson PA, Sutin A. Nonlinear Elastic Wave Spectroscopy (NEWS) Techniques to Discern Material Damage, Part I: Nonlinear Wave Modulation Spectroscopy (NWMS). Res Nondestruct Eval 2000; 12 (1): 17-30. 